\title{
A cultura dos "Coitados": trajetória social e sistema de arte.
}

João Domingues*

Resumo: O ensaio em questão tem como objetivo a apropriação da teoria proposta por Pierre Bourdieu, em especial a relação entre o espaço social e o lugar, para analisar as condições possíveis de serem percebidas no campo da produção da cultura (mais especificamente da produção cinematográfica) e a incorporação de agentes segregados espacialmente como produtores no campo constituído. Para tanto, foi selecionado um produto audiovisual recente - Cidade de Deus, de Fernando Meirelles -, cuja análise apresenta elementos que sugerem que a interseção entre a trajetória pessoal dos indivíduos e a hiper-realidade construída pela obra criam as condições de inserção de sujeitos como profissionais até então apartados do mercado formal de produção artística. A indicação prévia deste ensaio permite relacionar as condições da marginalidade assumida não apenas desfrute do consumo cultural, mas da própria atividade artística, ambos produtos de um mesmo habitus. É justamente neste habitus reiterado pelo cenário urbano que reside a possibilidade de integração dos sujeitos segregados territorialmente. Ao tratamento de "coitados", pretendemos sugerir que é desta incorporação simbólica, uma das possibilidades destes sujeitos de superar/aceitar os mecanismos societários de exclusão e assimilação no mercado formal de arte.

Palavras-chave: habitus; sistema de arte; trajetória social.

Abstract: This paper aims to discuss Pierre Bourdieu's theory, specially regarding the relationship between social space and place, to analyze the conditions given of being realized in the cultural production field (specially the movie production field) and the incorporation of spatially segregated agents as agents in the constituted field. With that purpose, a recent audiovisual product was chosen Cidade de Deus (City of God), directed by Fernando Meirelles - , presenting elements that suggest that the personal trajectory of individuals and hyper-reality constructed by the work create the conditions of insertion of the subjects as professionals up until that moment, aside from the formal market of artistic production. The previous indication of this paper allows the relationship of the assumed marginality conditions not only to enjoy the cultural consumption, but also to enjoy the artistic activity itself, both resulted of the same habitus. It is regarding this habitus confirmed by the urban scenery that lays the possibility of integration of territorially segregated subjects. When given the treatment of "poor", we aim to suggest that of this symbolical incorporation, a real possibility of those subjects to overcome/accept the exclusion and assimilation society mechanisms in the formal art market.

Key-Words: habitus; art system; social trajectory.

* Doutorando em Planejamento Urbano e Regional pela Universidade Federal do Rio de Janeiro. Professor Assistente do Curso de Graduação em Produção Cultural da Universidade Federal Fluminense (UFF). E-mail: joaolpdomingues@gmail.com.

Latitude, vol. 3, n¹, pp.06-21, 2009.

DOI: https://doi.org/10.28998/2179-5428.20090102 


\title{
A cultura dos "Coitados": trajetória social e sistema de arte.
}

\author{
"negro drama, \\ entre o sucesso e a lama." \\ Racionais $M c^{\prime}$ s
}

\section{Política cultural como campo}

Dizemos comumente das políticas culturais a existência de dois sentidos não concorrentes: o primeiro se apresenta em especial na relação entre os Estados e instituições de fomento, as diversas cadeias produtivas da cultura e seus agentes, sugerindo a importância econômica dos bens culturais (Canclini, 2001) e, portanto, da possibilidade de sua sistematização em programas públicos ou privados de apoio à produção de bens e à conservação da memória e do patrimônio; o segundo dirá da forma como os grupos sociais se apropriam de seus elementos simbólicos como meio de buscar garantias na vida política, apropriando-se de conteúdos morais para questionar os elementos de estigmatização, reforçando, desta forma, uma agenda político-prática de lutas por reconhecimento de novos direitos (Taylor, 1994).

Para a sociologia, as abordagens não escondem os conflitos do campo e lutas sociais pela legitimação dos saberes culturais, a formação das estratégias de produção, difusão e consumo de produtos e o embate pelo acesso e significação que cada grupo social dá aos seus bens raros de cultura. Para a construção do planejamento cultural, os dois sentidos são acumuláveis e inter-penetráveis, compreendidos como elementos expressos do campo dos direitos e constitutivos na centralidade das ações, em especial das políticas públicas.

É, portanto, nas políticas culturais onde se mediam e se reproduzem parte dos conflitos sociais e as maneiras como os processos de significação são mobilizados no campo autonomizado da cultura; seja na forma como os mercados culturais desenvolvem os bens simbólicos produzidos, seja na pauta prioritária das agendas públicas para a cultura em seus diversos níveis. Campo que, especialmente após a década de 60 , se expressa habitualmente na conexão e articulação de dois elementos principais: O primeiro dá conta da construção e consolidação de uma memória coletiva, que reforça o caráter marcadamente específico das práticas de sujeitos que elaboram e organizam suas expressões. $\mathrm{O}$ segundo pensará as estratégias de produção, difusão e consumo de produtos e o embate pelo acesso e significação que cada grupo social dá aos seus bens raros de cultura, onde as indústrias culturais e o setor de bens e serviços assumem cada vez mais uma função central de inserção na economia mundial, como um novíssimo depositário empregatício - ainda que precário, especialmente nos países de economia em desenvolvimento -, após as mudanças estruturais no campo do trabalho.

Do ponto de vista operacional, as políticas culturais alcançaram na contemporaneidade duas funções essenciais: a possibilidade de formulação de planejamentos públicos com vistas à materialidade da pluralidade cultural e a concretização de um mercado de consumo de massa, um espaço mediado entre a 
A cultura dos "Coitados": trajetória social e sistema de arte.

tolerância à diversidade cultural e a intensa transformação das práticas culturais em mercadoria.

É justamente neste último onde são determinados os meios de criação, circulação, comercialização e consagração das práticas e da produção artística e as estratégias de legitimação das linguagens dos mais diversos estilos artísticos, um "espaço estruturado de posições e tomadas de posição, onde indivíduos e instituições competem pelo monopólio sobre a autoridade artística" (Wacquant, 2005). É também neste espaço que observamos parte dos elementos de distinção social e de habitus artísticos, onde as variáveis educacionais atuam incisivamente e onde as variáveis urbanas aparecem com maior relevância em certos circuitos de promoção e produção da cultura. Ambas condicionam o processo de criação e apropriação das formas artísticas, ampliando ou limitando as possibilidades de acesso imediato ou mediato dos sujeitos sociais ao conjunto de possibilidades que as diversas práticas artísticas proporcionam, tanto em sua capacidade de acumular os capitais econômicos, ou no reconhecimento em si que o papel do artista incide no conjunto social.

Cabe relembrar que o domínio da linguagem artística e de sua transmissão - ressaltando a especificidade da cultura popular, e dos diversos processos de transmissão e acumulação dos saberes - está vinculado quase que exclusivamente ao modelo de educação erudita: nas escolas de artes plásticas, nas escolas de música, nas escolas de cinema, e quando muito podemos dizer, nas escolas fundamentais. $\mathrm{O}$ acesso aos recursos das linguagens promovem e reforçam o papel do artista e dos mediadores (sejam eles críticos, editores, os que, em geral, "criam os criadores", nas palavras de Boudieu) na divisão social do trabalho cultural.

Da possibilidade de estabelecer a política e a produção cultural como um campo, implica, portanto, recusar a prática artística suspensa das relações sociais, desmistificando qualquer resquício de caráter sagrado dos papéis artísticos, em especial nas formas de expressão contemporâneas que buscam segmentar e especializar o trabalho de criação. Desta feita, a consagração da autoridade da criação artística repousa sobre condições estruturais objetivas, e mesmo o ato de legitimação - o do especialista, crítico, aquele que domina os códigos efetivos do capital simbólico do campo e mesmo a capacidade de intervenção na captação dos recursos necessários às produções de grande porte - são determinados por instrumentos de apropriação objetivamente observáveis, expressos na distribuição dos agentes no espaço social.

Desta feita, para viabilizar minimamente uma leitura capaz de ensaiar o objetivo deste artigo, analisarei o campo da produção da cultura na forma como apresentada por Wacquant (op. cit.), sob três passos: a) a localização da produção cultural como sub-campo do espaço social; portanto imerso em relações de poder e regras próprias construídas na continuidade de legitimação do campo; b) uma topologia interna do campo, onde esperamos assinalar não somente as regras de funcionamento, mas especialmente a forma como as regras de funcionamento do campo administram parte da disposição dos agentes com posição privilegiada na operação da continuidade do campo; e c) a construção das trajetórias sociais dos indivíduos e coletivos no interior do campo, onde se demonstrará ser capaz de projetar suas formas de inserção como sujeitos legitimados socialmente para uma 
prática artística reconhecida.

A construção da prática artística como um campo é uma chave explicativa capaz de estabelecer as relações entre as estruturas objetivas da sociedade e as estruturas incorporadas nos agentes, a gênese das práticas e das preferências (Bourdieu, 2007:10). Reconfigurada como descrição estrutural do mundo objetivo sem dissociá-la das ações dos indivíduos, a prática artística é um elemento potencial para capturar a relação entre estrutura social e disposição (incorporações sociais transformadas em estruturas mentais pré-reflexivas) dos agentes como elementos de uma mesma realidade. Neste sentido, vários dos modelos propostos por Bourdieu para a apreensão das práticas sociais pela arte têm no consumo cultural - a distância ou proximidade em relação às normas e competências das práticas artísticas - a expressão das preferências e a constituição de uma unidade social pela razão prática, que apreende a multidimensionalidade e a pluralidade de lógicas de estruturação e ação na vida social.

É desta estruturação de força, da luta pela legitimidade dos códigos e do capital simbólico, a própria retradução simbólica de diferenças inscritas nas condições de existência. A difusão dos saberes culturais e, portanto, da possibilidade material de inserção nos circuitos consolidados de criação repousa sobre condições estruturais tanto dos esquemas mentais de significação (establishment e näif, incorporados nos sujeitos sociais como sistemas classificatórios mediadores da boa arte e da arte popularesca) quanto da possibilidade de sua inserção na reprodução do campo enquanto criadores.

A constituição do gosto pela arte e das preferências no consumo da arte adere em conformidade com a própria reprodução social, estratégias simbólicas de dominação. "A cultura dominante contribui para a integração real da classe dominante (assegurando uma comunidade imediata entre todos os seus membros e distinguindo-os das outras classes); para a integração fictícia da sociedade no seu conjunto, portanto, à desmobilização (falsa consciência) das classes dominadas; para a legitimação da ordem estabelecida por meio de estabelecimento das distinções (hierarquias) e para a legitimação das distinções. Este efeito ideológico, produ-lo (sic) a cultura dominante dissimulando a função da divisão na função da comunicação: a cultura que une (intermédio da comunicação) é também a cultura que separa (instrumento de distinção) e que legitima as distinções compelindo todas as culturas (designadas como subculturas) a definirem-se pela sua distinção em relação à cultura dominante" (Bourdieu, 1998:10-11).

$\mathrm{Na}$ construção objetiva deste processo - da oposição imediata entre dominantes e dominados - pode ser observada em um duplo movimento complexo: uma ilusão de integração de sujeitos, determinada por mecanismos muito precisos e rigorosos quanto a seleção de agentes que não necessariamente dispõem dos capitais requeridos à dominância do campo cultural; e a contraface dos mecanismos seletivos (permitidas no limite em que não se constituem como um projeto a superar), que, ao incorporar ou designar os agentes, realinham as hierarquias e promovem publicamente a possibilidade de integração de novos discursos.

Esta dimensão como caráter regulador do campo e das práticas, recriam as condições de promoção do "outro", revelando novas posses e atributos que se 
A cultura dos "Coitados": trajetória social e sistema de arte.

estabelecem à margem de um "estatuto natural do dominante", como uma estratégia submersa de sobrevivência na ausência não-capturada pelos dominantes. Quando publicizado, este emprego que escapa à cultura dominante realiza o reordenamento do campo - novas lutas pela apropriação simbólica - e introduz novos significados de produção da realidade estabelecidos em condições muito particulares.

As marcas distintivas também se referem a domínios, posses de bens sagrados e saberes. Inculcados como referência, a legitimidade em curso segue os padrões que consagram a autoridade da criação. O domínio da linguagem na diversidade de estilos artísticos não é exclusividade do consumo e desfrute, mas da possibilidade de criar e das distinções das classes profissionais de criação. A capacidade de articular um bom roteiro, o domínio da luz ou das técnicas de edição, os estudos de composição das personagens, todos os elementos de criação reforçam o caráter sagrado da arte e consagram a autoridade da criação artística. É, em parte, este domínio o reflexo e reiteração do gosto distintivo, capaz de reautorizar o processo produtivo, fazendo valer sua reprodução no conjunto das práticas sociais autorizadas como boa arte.

Às diferentes posições no espaço social correspondem também diferentes estilos de vida, processos que retraduzem simbolicamente as diferenças objetivas inscritas nas condições de existência, correspondentes as trajetórias dos sujeitos. As diferentes posições no espaço social - e, por conseguinte, a capacidade de cada agente em administrar o volume de capitais requeridos à posição no campo determinarão também a possibilidade que os agentes detém no domínio da criação, pela distribuição relativa de capital cultural, econômico e social, não apenas na determinação legítima da linguagem artística, mas de sua inserção nos circuitos legitimados. Especialmente ao capital social caberá a possibilidade de conexão entre os gostos (capital cultural, em geral) da real possibilidade da prática artística legitimada, bem como a determinação de uma pauta de execução do cenário de produção artística.

\section{O “coitado". Espaço reificado e trajetória}

Pesa para a construção do campo artístico (champ artistique) em Bourdieu (1996a) dois elementos principais: a disputa em torno dos critérios de valor comercial e artístico e a luta simbólica dos valores que normatizam o campo. Para Bourdieu, os agentes produtores se interpelam pela definição da linguagem e pelo valor dos trabalhos de acordo com o princípio predominante da percepção artística (Bourdieu, 2001). A suposição de Bourdieu é de que a "vocação artística" é um fenômeno do social, cujas "leis que regulam a vocação" se assemelham em princípio às que regem os domínios da linguagem produzidas no capital cultural (Bourdieu e Darbel, 2003).

Esta "vocação" está relacionada diretamente à capacidade que os agentes têm de interferir no campo produtivo, em especial nas etapas de captação dos recursos econômicos mínimos à possibilidade de produção. Aqui está expressa, no universo da organização dos meios de produção, uma agenda que pautará, segunda condições sócio-históricas, os bens passíveis de serem ou não produzidos 
e experienciados. No caso brasileiro, esta agenda, operada por agentes que supõem controlar o poder do que está sendo produzido, expressa a possibilidade de movimentação de imensos recursos públicos e privados que garantem a materialidade da produção, sem que se conste, necessariamente, que os critérios que pautam essa agenda detém qualidades intrínsecas do reconhecimento da boa arte.

Entendemos que parte de uma novíssima expressão de um capital artístico - marcado por uma experiência territorial que dá suporte e legitimidade aos significados buscados para parte da produção cultural brasileira, e que vem gerando imensos montantes de recursos financeiros - tem sido associado a expressão do capital cultural necessário à manifestação da lógica do campo e de um novo habitus artístico legitimador.

Este habitus é capaz de operar a inserção de certos sujeitos no processo produtivo e o desejo de se produzir como uma novidade, reivindicado pela agenda que reúne os agentes na operação do campo e na legitimação de seu capital simbólico. É a origem social e a trajetória que constroem a objetivação que marca as possibilidades e estratégias de integração dos sujeitos na disputa pela legitimação dos códigos artísticos. O capital artístico referido é o lugar reificado, que expressa não apenas a realidade material, mas os esquemas mentais interiorizados e as potencialidades inscritas nas posições que ocupam, elementos capazes de superar os mecanismos societários de exclusão da prática artística, sua aceitação e seleção no campo produtivo, e as possibilidades de mudança no campo.

Os agentes sociais se caracterizam pela posição que ocupam no espaço social, por posições relativas a outros agentes, onde, por sua dotação e volume de capitais, se determinam as condições de hierarquização social traduzidas pelos elementos de distinção manifestos em mecanismos de exclusão mútua. Na visão de Bourdieu, as diversas posições ocupadas pelos agentes no espaço social retraduzem-se no espaço habitado, como uma "espécie de simbolização espontânea do espaço social" (Bourdieu, 2003:160), onde a própria noção de campo se manifesta como um "espaço social fisicamente objetivado". A estrutura do espaço social (lógica das distinções e hierarquizações sociais) se manifesta sob a forma de oposições espaciais, onde o princípio de hierarquização do espaço social habita no espaço físico, exprimindo as distâncias sociais. A proximidade dos agentes no espaço físico permitiria, assim, a capacidade que o espaço social tem em favorecer a acumulação de capitais e a reprodução social; "uma parte da inércia das estruturas do espaço social resulta do fato de que elas estão inscritas no espaço físico e que não poderia ser modificadas senão ao preço de um trabalho de transplantação" (Bourdieu, 2003:161).

O espaço social reificado sugere que os processos de segregação espacial determinam as condições de distanciamento físico e simbólico dos que não possuem o volume de capitais necessário às diversas formas de mobilidade social. Tal como os agentes dispersos pelo território, a disposição dos bens e serviços tendem a reproduzir a lógica dos espaços sociais fisicamente objetivados, donde resultam as concentrações dos bens mais raros - e de seus proprietários - em certos lugares do espaço físico. Pari pasu, a lógica de cada campo determinado no espaço social tende a se sobrepor aos espaços sociais reificados; a proximidade no espaço 
A cultura dos "Coitados": trajetória social e sistema de arte.

físico permite que a proximidade no espaço social produza seu efeito de facilitar e favorecer a acumulação de capitais. $\mathrm{O}$ espaço tem uma capacidade, por ser lugar da proximidade ou da distância que aplicam aos agentes, de favorecer acumulação de capitais e a reprodução social, ou seu inverso.

Especialmente na indústria audiovisual brasileira, a relação entre este habitus legitimador e as possibilidades de integração num mercado super-seletivo são partes interdependentes deste novíssimo processo, solução contemporânea para a apreensão de um universo que tenta expressar as relações de violência física e moral de territórios das metrópoles brasileiras com o apego de estratégias próprias de encenação. $\mathrm{O}$ espaço social reificado é ele próprio, em alguma medida, a estrutura mental dos agentes territorialmente fixados.

Este novo capital artístico se impõe sobre um homologia entre a posição que o agente ocupa no espaço social e no espaço físico. É um capital artístico que origina uma arte baseada num realismo exacerbado, onde variadas expressões poéticas colocam em evidência o território marginalizado nas práticas referentes do campo artístico. Marca, portanto, a possibilidade de analogia na expressão entre o espaço-violência encenado e o espaço vivido, como um habitus auto-referente.

Em especial, são os agentes que habitam estes espaços físicos que podem apropriar-se de um estratégia de inserção, vista a partir de sua própria condição "excluída" e somente a partir de sua condição "excluída", narrativa de um cenário que questiona a ordem social hegemônica sem precisar romper com ela. Abre para a questão todo uma nova sorte de léxicos a utilizar: "ardor", "pureza" e "o belo" são substituídos por "vida real", "cruel", "verossímil". A representação que se faz do espaço também gera um efeito concreto nas práticas dos agentes, onde também a apropriação física do espaço é relacionada às lutas em torno das representações destas mesmas práticas, como um domínio altamente especializado das experiências e da construção mental esquemática de uma mesma prática coletiva.

Para a disposição de um discurso mediano sobre esta lógica de integração, é o papel do "coitado", o ausente da esfera pública que muito pode fazer "se tiver uma chance", mas que impõe sua assimilação na prática artística por sua condição marginal. É este "coitado", marginal, o mesmo que não dispõe dos recursos econômicos suficientes para arcar com os custos de seu ingresso às obras produzidas ou ao campo de produção (seja ele nas técnicas de atuação, direção, edição ou captação de recursos e pauta da agenda produtiva), mas que se torna uma figura facilmente sedutora aos consumidores da indústria audiovisual no Brasil. Aproveitando-se de uma disposição "a pretensão à glória", e da "fala de artista", que "continua movendo, as ambições pessoais nesses locais, marginalizados, de muitos modos, na cidade do Rio de Janeiro" (Zaluar, 1985), é na figura curiosa do vitimado que se enxerga a possibilidade de seu aproveitamento num regime muito particular da produção cultural. Quanto aos anseios de sua inserção, trata-se de uma medida legítima, tanto aos interesses pessoais mais imediatos - da possibilidade da criação artística, quanto de seu aproveitamento num mercado de trabalho que retribui bem quanto ao valor do trabalho, interessado em suas características - quanto da possibilidade de mobilidade e ascensão social.

Restaria dizer que a estratégia de reconversão das classes populares às 
classes "iluminadas da arte" assume feição nada óbvia, em especial no plano das linguagens contemporâneas. A inserção de um indivíduo neste plano se dá por sua posição no espaço social e o gosto artístico referente às suas experiências, enfrentando ou acordando os limites impostos pelo sistema de reprodução da arte - e, por conseguinte, dos gostos, no limite em que as propriedades que operam no distanciamento territorial presentes no espaço físico e transformadas em capital simbólico são uma das "mediações através das quais as estruturas sociais se convertem progressivamente em estruturas mentais e sistemas de preferência" (Bourdieu, 2003:162). É desta fronteira que se constrói a fundação mais controversa de parte do campo da produção artística, em que a linguagem dos "coitados" - e a tentativa de promover um diálogo "por dentro" - opera nos vazios de indiferença do sistema de arte, sendo em parte repulsa sobre as condições reais de pobreza, em parte comodismo com a integração real destes sujeitos individualizados como possibilidade de mobilidade social.

Dado que a capacidade de dominar o espaço social depende do capital que se possui, a proximidade no espaço físico permite que a proximidade no espaço social produza todos os seus efeitos, alimentando os processos de distinção social. São os elementos de distinção que operam o cenário de integração; via-de-regra, integração parcial, intermediária - enquanto prática artística - do périplo da concreção material da obra audiovisual. O domínio das linguagens codificados do cotidiano do "coitado" e ao "coitado" é um conteúdo que reúne os elementos mínimos de integração.

No caso, a origem social e a trajetória constroem a objetivação que marca as possibilidades e estratégias de integração dos sujeitos no campo artístico. Entender a trajetória e o habitus próprio desta origem social possibilita compor biografias comuns e uma série de posições que os agentes ocupam no espaço social, tal como um sistema integrado de padrões identitários como elemento de sua inserção motivada no campo da prática artística. É em parte desprezo por sua condição, parte necessidade de transformação de sua condição, o esquema operativo destas narrativas simbólicas, e esta dialogia marca, em geral, o argumento da obra e a seqüência lógica das cenas editadas.

A estratégia apropriada nesta forma audiovisual descreve os limites e etapas de elaboração de uma mitologia urbana presente no imaginário social, reivindicando radicalmente a autoridade de demonstração da violência operada por sujeitos vitimados por uma "cidadania incompleta" ou "a completar". De forma mais clara, Bourdieu propõe que a apropriação do espaço físico expressa as distinções sociais (retomando seu projeto de construção conceitual do espaço social), quanto que a doxa dominante atribuirá propriedades ao espaço físico que são, na verdade, relações sociais. A descrição violenta dos territórios constrange qualquer possibilidade de sua integração com o corpo extenso da cidade, ampliando o poder de construção do discurso histórica da favela como o espaço do "perigo a ser erradicado pelas estratégias políticas que fizeram do favelado um bode expiatório dos problemas da cidade" (Zaluar, 1985).

Este "coitado" é o perigo a ser controlado, o pária urbano representado em uma concepção dualista de cidade, incapaz de inserir-se nas relações "autoreguláveis" do espaço urbano sem o auxílio necessário dos que estão "de fora". 
A cultura dos "Coitados": trajetória social e sistema de arte.

Desta feita, não apenas sua apropriação como o sujeito a documentar visualmente, mas o próprio sujeito produtor $\mathrm{em} \mathrm{si} \mathrm{-} \mathrm{embora} \mathrm{não} \mathrm{necessariamente} \mathrm{de} \mathrm{si} \mathrm{-} \mathrm{é} \mathrm{a}$ apropriação de um discurso que ao mesmo passo constrange sua trajetória como produtor (no limite em que a obra audiovisual necessita de uma apropriação roteirística, onde se supõe um caráter ficcional) através da construção simbólica de seu espaço "de origem", em geral consumida por sujeitos de diferentes habitus.

Este vitimado se insere no mercado, não como alguém que necessariamente - detém ou luta por legitimidade "cultural", mas se impõe sobre o resto da sociedade como alguém que promove uma experiência mediada ao espectador ou ouvinte com a realidade social concreta com a qual deseja não ter contato. Este agente detém uma condição muito especial, como que um capital cultural relacionado ao espaço social reificado. É pelo domínio expresso na intimidade com seu espaço físico que se desenvolve uma capacidade de ação de um estilo de vida que se submete às necessidades mais urgentes dos conteúdos audiovisuais. Neste contexto troca-se, por intermédio de outros agentes do campo, o conhecimento sugerido da vida reificada pelo conhecimento sugerido da atuação dramática. A gíria cotidiana e sua força de expressão hiper-real pela técnica de posicionamento, disposição da voz, construção corporal da personagem ante a câmera.

Aqui se opera uma estratégia de inversão interessante. Este habitus distintivo dos sujeitos segregados é submetido à operacionalidade última da produção audiovisual. A trajetória de vida dirá muito mais à possibilidade do agente em ser selecionado para a prática do que, necessariamente, quaisquer outros ativos previamente recomendáveis ao domínio da prática audiovisual. O habitus distintivo é o controle dos códigos aceitos como violentos, o efeito do lugar ao invés do capital cultural academizado, mas atuando ele mesmo como o capital necessário da valorização do hiper-real demonstrado. A figura central que dá ênfase ao processo é o negro pobre e favelado, de "índole" violenta, capaz de assegurar sua posição na "guerra urbana" sob o despejo de qualquer ação que indica o desapego à vida alheia ou às leis.

A oposição a este habitus é justamente o que dá sentido à narrativa dominante, o correspondente de uma esperança de integração por uma vida justa, embora ancorada nas dificuldades próprias da vida cotidiana da favela, e que por obviedade adere ao afeto mais imediato dos consumidores médios, reiterando a violenta significação de que "ele pode conseguir, se tiver uma chance", adicionando ao estigma do favelado uma outra significação: "veja, ele pode atuar a própria vida no cinema". Vida cotidiana e expressão cinematográfica desta forma se encontram, afastadas pela distância física da cidade e dos confortáveis assentos da sala de exibição, já que o mais comum das relações na cidade vem sendo a suspensão das causas sociais da violência e a necessidade de enquadrá-la numa experiência de aproximadamente duas horas, onde novos elementos podem assim ser adicionados (a boa música, a câmera "solta", a boa fotografia) como estratégia de educação do olhar e conformação do mal-estar sobre a violência e os violentados. Sua integração carrega, assim, alto grau de exotismo no tratamento dado pelas políticas culturais à pobreza. Em geral, o espectador suporta a condição do "negro-favelado-bandido" somente porque ao "negro-favelado-honesto" é dada 
a chance de erguer-se ante às dificuldades apresentadas, como o motivador necessário de sua superação.

O jogo-jogado está presente em todos os participantes do processo: se o espaço social está inscrito tanto nas estruturas físicas, quanto nas estruturas mentais dos agentes, é pela obra artística que sintetiza o domínio do campo que esta se manifesta a violência simbólica como violência despercebida, reiterando o estigma espacial sem romper com os superficialismos das análises cotidianas. Os que não possuem o capital necessário "são mantidos à distância, seja física, seja simbolicamente, dos bens socialmente mais raros e condenados a estar ao lado de pessoas ou dos bens mais indesejáveis e menos raros" (Bourdieu, 2003:164), ou mesmo construir a intenção de se apropriar deles. No que toca ao processo de transformação das representações em torno do espaço, os excluídos física e simbolicamente, estão destinados a permanecer nos lugares indesejáveis, onde a hiper-realidade e a realidade concreta se descolam com imensa facilidade. No caso, o destino do "negro-favelado-bandido" é sua remissão ou morte, enquanto que ao "negro-favelado-honesto" é destinado uma vivência posterior mais amena, como um presente para a boa conduta.

O cenário dramático e as imagens expressam uma propriedade em questão da estética hiper-realista que não abandona as classificações dualistas, mas reitera este "dualismo de representações tão presentes no pensamento e que criam um outro estrangeiro, distante e oposto" (Zaluar, 1985). A cidade representada é um Rio de Janeiro incompleto, sua representação midiática como depositário da desordem, e o favelado como o sujeito da desordem a reprimir, uma "categoria social que não participou de sua constituição, resultado de uma subordinação extrema e expressão de um imenso diferencial de poder" (Machado, 2002) que sintetiza a construção simbólica dos "problemas da cidade" e a decadência urbana. Já a integração do sujeito da atividade dramática apresenta contornos levemente diferentes; se a inserção dos "coitados" se dá por um processo seletivo baseado no domínio de ser estigmatizado, reiterando - inclusive pela aparência física - a figura do desordeiro, tem-se a noção que as manifestações culturais dos pobres não se esgotam nas fronteiras que se estabelecem entre eles e o resto da sociedade, mas, ao contrário, são altamente organizadas. O limite do processo é buscar qual o sujeito apto a narrar sua história, ciente seu habitus também o auxilia para enxergar a história narrada pela hiper-realidade com mediações mais refinadas que o consumidor médio, expressando significados distintos para os que de fato vivem a situação de pobreza.

\section{3- Cidade de Deus. Os limites da significação da violência.}

Cidade de Deus é uma adaptação de romance homólogo de Paulo Lins, e narra a história do desenvolvimento do tráfico de drogas no conjunto habitacional da Zona Oeste do Rio de Janeiro, dando início a uma série de produções onde o espetáculo da violência urbana é seu mote central.

A trama da obra gira em torno de duas personagens, atravessando suas histórias em meio há três décadas; Buscapé, jovem sonhador, que encarna a possibilidade de ascensão social num meio urbano amplamente degradado, e Zé 
A cultura dos "Coitados": trajetória social e sistema de arte.

Pequeno, que sintetiza a visão do diretor sobre a violência dominante na favela. Misturando linguagem documental (como a imagem final, de Sergio Chapelein no Jornal Nacional em 1979, noticiando a prisão de Mané Galinha), um padrão de narrativa cinematográfica clássica (uso de flashbacks e eventos em seqüência, narração de um protagonista como o ponto de vista central da trama), formato próximo ao videoclipe, qualidade técnica impressionante (jogo de edição, câmera na mão, fotografia "suja") e boa estratégia publicitária, Cidade de Deus conseguiu atingir um grande número de espectadores (3,2 milhões) para a média nacional, conquistando também grande espaço no mercado internacional, com uma mistura de western no caos urbano carioca.

O filme foi cercado de polêmicas desde o nascedouro. A locação escolhida Cidade Alta - foi liberada pelo governador Anthony Garotinho após muita negociação, e as filmagens só puderam começar após o envio do roteiro e aprovação do chefe do tráfico local. Na estréia pública do filme, um homem foi preso durante a sessão no maior complexo de cinemas do Rio, acusado de trabalhar nas operações de tráfico de drogas.

A vida no conjunto habitacional é retratada em três décadas, onde a degradação vai se ampliando com o decorrer do tempo, mostrando como se deram os conflitos internos em Cidade de Deus pelo controle do tráfico de drogas. A sociabilidade no espaço é retratada de forma bastante precária, o sentido de privação de oferta de bens aos moradores e de seu abandono e restrição ao conjunto da cidade é expressado logo ao início do filme: "a gente chegou na Cidade de Deus com a esperança de encontrar o paraíso, um monte de famílias tinha ficado sem casa, por causa das enchentes e de alguns incêndios criminosos em algumas favelas. A rapaziada do Governo não brincava... não tem onde morar, manda prá Cidade de Deus. Lá não tinha luz, não tinha ônibus, não tinha asfalto... mas num governo dos ricos, não importava o nosso problema. Mas como eu disse, Cidade de Deus não fazia parte do cartão-postal do Rio"i. O roteiro conta ainda os clichês próprios da cinematografia contemporânea, como o nível banal de estetização da violência ou a construção bastante pobre da rivalidade entre os personagens Zé Pequeno e Mané Galinha.

O interesse do ensaio é entender o sistema de integração dos jovens atores nos papéis centrais da obra. A fala do diretor Fernando Meirelles já expressa um pouco a estratégia: "enquanto a gente tava trabalhando no roteiro, (...), a gente já tinha na cabeça que teríamos que fazer esse filme com atores não- profissionais. Eu queria que o espectador olhasse o Zé Pequeno e enxergasse o Zé Pequeno, não algum ator fazendo o Zé Pequeno, então a ideia de ter algumas caras desconhecidas era justamente para tirar esse filtro, o espectador se relacionar direto com o ator, então se relacionar direto com o personagem. Tudo isso eu achei que poderia me trazer a verdade que eu queria no filme" ii.

Resta pensar, que as relações do campo se manifestam, via de regra, também em conseqüência das normas de mercado, vistas pelas leis de renúncia fiscal e da mediação do Estado como agente financiador. Coube à produção executiva do filme escapar desta relação, com o risco (calculado, sem dúvida) de arcar com a maior parte dos custos diretos de produção. A encenação com atores "reais" torna também os custos imediatos de produção mais baixos no pró-labore pago, recalculando as despesas para a preparação dos atores.

Tal como no processo literário de Paulo Lins, revelou-se aqui uma 
estratégia de sobre-elevação do habitus marginal, capaz de narrar por dentro, a partir da ausência de suas falas na esfera pública e do aproveitamento de suas experiências pessoais, parte das contradições sociais da violência e da pobreza no Rio de Janeiro contemporâneo. Como nos revela Ribeiro (2003: 127), "pode-se dizer, assim, que se cumpria "aqui" o que emblematicamente Geertz denominou de "estar lá" etnográfico, já que Lins, melhor do que ninguém, tanto viveu na Cidade de Deus quanto estudou a história do tráfico de drogas naquela comunidade a partir dos preceitos - e das ambigüidades - presentes na etnografia e no trabalho de campo, o que poderia situar sua narrativa como uma espécie de automodelagem artística" (grifo nosso).

Durante o processo, foram feitas duas mil entrevistas com jovens da Rocinha, Cidade de Deus, Chapéu Mangueira, Vidigal e Santa Marta, sendo posteriormente selecionados duzentos destes jovens para oficinas com Guti Fraga, diretor do grupo Nós do Morro. O processo de seleção foi motivado, em grande parte, pelas características físicas dos sujeitos segregados (negro/pobre/favelado): "a gente fez 2000 entrevistas com pessoas interessadas em fazer uma oficina de ator, a gente nunca falou que teria um filme na ponta, depois junto com a Katia, com o Guti e toda a turma do escritório, a gente ia escolhendo os garotos... esse é uma cara interessante, esse é uma cara feia, vamos trazer, esse é bonitinho, esse aqui é engraçado... muito subjetivo, era o carisma o nosso critério"iii.

A escolha do diretor em trabalhar com atores desconhecidos (atores a serem feitos), legitimou-se, em sua fala, por enfrentar na expressão simbólica da obra as questões da criminalidade urbana violenta carioca a partir da fala daqueles que "estavam no não-lugar destas discussões, aqueles que majoritariamente mais sofrem com as tragédias geradas pela violência urbana: os mesmos outros fantasmagóricos que vivem nas favelas e periferias das grandes cidades brasileiras" (Ribeiro, 2003). O processo, entretanto, não suspende o grau de integração também violenta destes sujeitos ao processo de produção da cultura, dos níveis de nova estigmatização que os moradores de Cidade de Deus sofreram após o lançamento do filme - que evidentemente são relações que se movem acima da produção cinematográfica em si -, ou das possibilidades de seqüência de trajetória dos selecionados na vida artística.

Os selecionados da oficina foram aos poucos modelando sua experiência pessoal - a condição inicial de sua integração na produção - à temática referida em Cidade de Deus. O espaço de suas vidas, contudo, sofreu por igual um filtro seletivo, característico da narração cinematográfica: "porque na oficina, a galera foi pegando a essência da história... tudo bem, esse filme fala sobre guerra, sobre o tráfico de drogas... então nas nossas improvisações, era tudo relacionado ao filme"iv. A vida dos "coitados" improvisada nas oficinas e retratada no filme captura bem o que interessa atualmente ao mercado de arte e da pobreza retratada como fenômeno funcional à reprodução do seu sistema. A estratégia da preparação foi a execução do mais alto grau de realismo, capaz de expor a verossimilhança da obra à apropriação da vida real.

Se não inaugura, Cidade de Deus marca uma concepção muito forte de parte da produção da cultura sobre uma estética da violência, que não escapa à significação que limita a violência ao território da favela, mas que possibilita a 
A cultura dos "Coitados": trajetória social e sistema de arte.

tradução da imagem de novos jovens no imaginário público como sujeitos "além" da pobreza.

\section{4- E o que resta aos "coitados"?}

Inseridos por força de estratégias societárias num "campo de lutas, no interior do qual os agentes se enfrentam, com meios e fins diferenciados, conforme sua posição na estrutura do campo de forças, contribuindo assim para a conservação ou transformação de sua estrutura" (Bourdieu, 1996: 50), estes "párias urbanos selecionados" enxergam a possibilidade de mobilidade social tal como atores reais - no limite em que as alterações no campo devem ser entendidas como mudanças nas posições relativas dos atores no campo, onde podem, de fato operar estabelecer estratégias de subversão das regras do campo e da doxa conservadora.

O novíssimo relevo deste processo se manifesta sob condições sóciohistóricas que marcam modificações intensas na organização da cultura: sua importância no crescimento dos Produtos Internos Brutos dos países, seu uso como como elemento de socialização, sua vinculação às estratégias de renovação das políticas sociais e da normatividade do direito. Como cenário complementar, a cultura surge como um elemento central na reorganização da economia urbana, sendo objeto de preocupação política das cidades.

Caberia aqui situar minimamente duas possibilidades de reconhecimento da trajetória deste sujeito na expressão midiática como função da espetacularização do cotidiano. O primeiro nível de inserção dos "coitados" pode ser entendido como projeto coletivo, agindo em sintonia com o ambiente midiático, onde o "coitado" se entende como um ator efetivo, capaz de "usar" a mídia convencional (por meio de capitais acumulados nas tecnologias sociais) como projeto para seu "aparecimento" para o conjunto social. Evidentemente, esta tentativa é possível pelas novas condições materiais de desenvolvimento das linguagens audiovisuais, muito mais baratas e de acesso codificador mais simplificado. O segundo nível é de sua inserção individual e fragmentada, tal como um vitorioso que sobrevive aos filtros naturalizados da especialização técnica do mercado de trabalho. Se a relação imediata não está inserida num projeto coletivo, é evidente que nos processos mediados nada pode remover deste indivíduo, "a favela" - compreendida como um status negativo em parte da compreensão pública. De qualquer forma, o espetáculo do cotidiano violento e sua inserção adquire relação sincrônica entre lógica midiática e paradigmas do mercado (Paiva, mimeo). Uma equação complexa, capaz de articular a produção audiovisual - como um dos condutores da cultura global -, e as dificuldades em se entender a diversidade das favelas para se entender a cidade de hoje, que acolhe e rejeita os territórios segregados espacialmente.

No processo sociohistórico uma substituição dos projetos de elevação da cultura como ferramenta de emancipação social, educação para a civilidade e transformação, apoiadas em uma perspectiva nacional-popular, das relações de dominação. $\mathrm{O}$ aparato público, organizado em geral na América Latina em torno de relações entre os mecanismos de poder do Estado e o capital privado que organiza parte da vida social pela produção de bens, escora-se na cultura sobre 
uma outra dimensão. O universo do planejamento cultural, já pensado na estrutura democrática do Estado, guarda elementos de forte representação destes interesses, demonstrando diferentemente do projeto iniciado na década de 60, a integração de jovens em situação de marginalidade urbana por filtros seletivos muito específicos. $\mathrm{Na}$ verdade, é o planejamento cultural público em referência à atividade cultural privatizante, a ferramenta expressa desta relação, motivando a incorporação de alguns poucos no universo formal - cada vez mais exigente quanto à técnica especializada - do mercado de trabalho artístico.

Cabe ressaltar a pergunta: o que constrói a legitimidade de incorporação destes atores? Sua integração, antes de tudo, desvencilha-se da clareza de um projeto popular constituído, para dar ênfase a uma vitória pessoal inequívoca. Vitória que, assimilada pelos agentes que lhe reconhecem no imediato da vida social traspassada à tela de cinema, não apenas orgulham-se de sua conquista, mas compreendem que este caminho é o guia de sua emancipação material e simbólica. Aceitar o ato da vitimização do "coitado" é, antes de tudo, uma saída legítima aos que são renegados social/espacialmente em tornar seu caminho tortuoso, uma universo de conquistas possíveis, reais e legitimadas. Sua presença como protagonista, encenada sob as condições de sua exclusão, e somente por elas, pode ser finalmente concretizada.

Cidade de Deus é um filme que permite uma ampla discussão sobre o modo de inserção de certos sujeitos - atomizados - no mercado formal e profissional de arte, indicando caminhos posteriores de sua possível trajetória futura. Tentamos centrar a discussão na perspectiva, nada simples, do aproveitamento de sujeitos em situação de segregação espacial na produção da obra, sugerindo que a possibilidade de sua integração tem por característica principal a reafirmação de um determinado habitus (princípio gerador das práticas) que expressa sua marginalidade. O auxílio de Bourdieu, e de seus conceitos principais, se mostrou uma ferramenta importante para compreender os mecanismos de inclusão de sujeitos privados de certos capitais no cenário produtivo da cultura, num projeto que pretende realizar-se enquanto uma arte política, capaz - mesmo que de maneira inicial e precária - rascunhar os processos sociais e culturais que atravessam os meios de produção da cultura na atualidade.

Tratamos de cadeias produtivas (sub-campos) com lógicas operacionais muito diversas, e mesmo que tenhamos como modelo de análise um cinema fortemente amparado no Estado - no limite, responsável por mediar o processo produtivo e o compromisso com a cidadania -, o direito à produção artística aparece como um projeto a realizar, posto o esquecimento do território como uma categoria restringida pelos processos sociais de concretização da atividade cultural produtiva ou reconhecida como boa arte. Mesmo que possamos estabelecer uma retradução simbólica de diferenças inscritas nas condições de existência e relembrando a impossibilidade de estabelecimento de uma cultura urbana homogênea, o território marginalizado é esquecido como uma categoria essencial para o direito à produção artística, seja no planejamento de construção de equipamentos urbanos culturais, seja como um item para a distribuição dos investimentos necessários à produção de bens; o processo de seu "aproveitamento" é a seleção de alguns poucos agentes.

É o habitus marginal que garante sua integração, este mesmo habitus 
A cultura dos "Coitados": trajetória social e sistema de arte.

precário, revisitado pelo efeito de lugar como a chave de integração, a possibilidade de sua aceitação pelos mecanismos de exclusão e seleção do campo produtivo, e, portanto, da possibilidade de mudança no campo. É a sedução de ver um "coitado" "vencendo" que faz esquecer/suspender que o limite de sua integração é duplamente violenta. Seria menos violento saber que estes mesmos moradores, o centro do filme, não dispõe das condições de acesso aos meios de reprodução cinematográfica? Centros culturais, salas de cinema, produtoras não estão na favela, expõe a composição de uma cidadania fragmentada e restrita é alvíssaras das dificuldades de apropriação da linguagem artística - em especial pela pouca disponibilidade de capital econômico - e do capital artístico. Sua inserção é subordinada e precária, carregada de forte estigma, elemento capaz de acionar sua eliminação imediata do campo e fazê-los lembrar que seu lugar é a favela não mais representada. $\mathrm{O}$ conhecimento das regras do jogo permitem àqueles que tem o poder de defini-las de posicionar-se de forma dominante no campo e da representação do mundo social. Os dominados jogam o jogo, no limite em que seu acúmulo de capitais permite que joguem, podendo estabelecer relações causais de transformação ou permanência das regras do jogo e da constituição do campo. Neste caso, a pobreza aparece como um fenômeno funcional à reprodução do sistema de arte, tal que quando os "coitados" produzem no imaginário coletivo. Mesmo com este cenário esquemático e redutor, os "ausentes" podem partilhar novos projetos, recusando qualquer redução exótica, operando politicamente a necessidade de expor a cultura heterogênea produzida nas favelas, vinculando o território de pertencimento destes sujeitos, e de desconhecimento da cultura dominante.

Mas a pretensão de formulação de uma arte política - mesmo que genérica - traz possibilidades de transformação na sociabilidade urbana, ressaltando que os caminhos para a inserção dos "coitados" não são de fácil solução, suas oportunidades são raras. No momento, embora sua inegável criatividade revele possibilidades de reconhecimento no campo simbólico, este reconhecimento permanece submetido aos "mecanismos de reprodução de um modo fragmentado e fortemente hierarquizado de integração urbana" (Machado, 2002).

\section{Bibliografia:}

BOURDIEU, Pierre. A Distinção: crítica social do julgamento. Porto Alegre: Zouk, 2007. A Miséria do Mundo. Petrópolis: Vozes, 2003.

A Produção da Crença: contribuição para uma economia dos bens simbólicos, Porto Alegre: Zouk, 2001. As regras da arte: gênese e estrutura do campo literário. São Paulo: Companhia das Letras, 1996. . O Amor Pela Arte: museus de arte na europa e seu público, Porto Alegre: Zouk, 2003.

O Poder Simbólico. Rio de Janeiro: Bertrand Brasil 1998. Razões práticas: sobre a teoria da ação. Campinas: Papirus, 1997. 
CANCLINI, Nestor García. Definiciones en transición. Buenos Aires: CLACSO, 2001. MACHADO, Luiz Antônio. A continuidade do "problema da favela". In OLIVEIRA, Lucia Lippi (org.). Cidade: História e Desafios. Rio de Janeiro: Ed. FGV, 2002. PAIVA, Raquel. Política de minorias: comunidade e cidadania. Mimeo.

RIBEIRO, Paulo Jorge. Cidade de Deus na zona de contato: alguns impasses da crítica cultural contemporânea. Revista de Crítica Literária Latinoamericana Ano XXIX, No 57. Lima-Hanover, 2003, pp. 125-139.

TAYLOR, Charles. Multiculturalismo. Lisboa: Piaget, 1994.

WACQUANT, Loïc. Mapear o campo artístico. Sociologia, Problemas e Práticas № 48. Lisboa, 2005.

ZALUAR, Alba. A máquina e a revolta: organizações populares e o significado da pobreza. São Paulo: Brasiliense, 1985.

6- Filmografia

Cidade de Deus, (Brasil, 2002). Direção Fernando Meirelles.

i Fala do personagem Buscapé. Cidade de Deus, direção de Fernando Meirelles, 2002.

ii Fala de Fernando Meirelles, dvd extra do filme Cidade de Deus, 2002.

iii Fala de Fernando Meirelles, dvd extra do filme Cidade de Deus, 2002.

iv Fala de Leandro Firmino da Hora,dvd extra, Cidade de Deus. 